ARGONNE NATIONAL LABORATORY

9700 South. Cass Avenue

Argonne, Illinois 60439

CONF-850810--7

DE85 006840

\title{
ANALYSIS OF STRATIFIED FLOW MIXING
}

by

S.L. Soo and R.W. Lyezkowski

Energy and Environmental Systems Division

\section{DISCLAIMER}

This report was nrepared as an account of work sponsored by an agency of the United States Government. Neither the United States Government nor any agency thereof, nor any of their employees, makes any warranty, express or implied, or assumes any legal liability or responsibility for the accuracy, completeness, or usefulness of any information, apparatus, product, or process disclosed, or represents that its use would not infringe privately owned rights. Reference herein to any specific commercial product, process, or service by trade name, trademark, manufacturer, or otherwise does not necessarily constitute or imply its endorsement, recommendation, or favoring by the United States Government or any agency thereof. The views and opinions of authors expressed herein do not necessarily state or reflect those of the United States Government or any agency thereof.

Submitted to the ASME Session

"Natural Convection in Stratified Flows"

at the

23rd National Heat Transfer Conference

Denver, Colorado

August 4-7, 1985 


\title{
ANALYSIS OF STRATIFIED FLOW MIXING
}

by

\author{
S.L. Soo* and R.W. Lyczkowski
}

\begin{abstract}
The Creare 1/5-scale Phase II experiments which model fluid and thermal mixing of relatively cold high prossure injertion (HPI) water into a cold leg of a full-scale pressurized water reactor (PWR) having loop flow are analyzed and found that they cannot achieve complete similarity with respect to characteristic Reynolds and Froude numbers and developing hydrodynamic entry length. Several analyses show that these experiments fall into $t$ wo distinct regimes of mixing: momentum controlled and gravity controlled (stratification).
\end{abstract}

\section{INTRODUCTION}

One process necessary to evaluate the consequences of an overcooling transient in full-scale pressurized water reactors ( $P$ WRs) is to computer model the transient and steady-state three-dimensional fluid and thermal mixing phenomena. Such calculations provide the boundary conditions for calculating the thermal stress in the primary vessel's metal walls. ${ }^{1}$ in order to have confidence in the accuracy of these thermal-hydraulic calculations, a validation process is necessary for the calculational methods. This process has begun 2 by successfully analyzing several of the atmospheric pressure 1/5-scale Phase II fluid and thermal mixing experiments, conducted ai Creare, inc. ${ }^{3}$ A computer program was used which is based on the fundamental relations of mass, momentum, and energy conservation. ${ }^{4}$ Generic full-scale PWR model computations having high pressure injection (HPI) were also performed ${ }^{2}$.

*Consultant, University of Illinois at Urbana-Champaign Urbana, Illinois 61801 
The purpose of this paper is to address the issues of scaling, turbulence, and stratification. This is necessary because complete dynamic similarity cannot be achieved between the generic full-scale PWR model computations and the small-scale experiments. Dissimilarities exist not only in the characteris ic Revnolds and Froude numbers, but also because of the lack of fully developed flow.

While the HPI Froude number, $\mathrm{Fr}_{\mathrm{HPl}}$, can be matched, the Reynolds number of loop flow, $\mathrm{Re}_{\mathrm{LOOP}}$, and the inlet length are quite different. The computer program, however, has the capability of modeling both the full-scale PWR and the small-scale experiments.

\section{BRIEF DESCRIPTION OF CREARE 1/5-SCALE, PHASE II EXPERIMENTS}

For readers unfamiliar with these experiments, $\rightarrow$ brief description follows. A total of 26 fluid and thermal mixing tests were performed, three of which involved mixing of fresh and salt water. A total of six tests had zero loop flow. Figure 1 shows the geometry of the Creare $1 / 5$-scale Phase II experimental facility. It is a transparent acrylic facility designed for operation near atmospheric pressure. Major linear dimensions are reduced from typical values of Westinghouse (W) and Combustion Engineering (CE) PWR's by approximately a factor of 5 . Hence, the facility is referred to as a $1 / 5$-scale model.

The HPl water is injected through one of three injector locations referred to as:

- "near $60^{\circ} "$

- $" \mathrm{far} 60^{\circ} "$

- "near small"

The designations "near" and "far" refer to distances from the simulated vessel, $60^{\circ}$ refers to the angle of inclination of the injectors relative to horizontal and "small" refers to a 0.275 in. $(0.007 \mathrm{~m})$ inner diameter injection line perpendicular to the cold leg pipe. These three injectors are shown in Figure 1. The "near $60^{\circ}$ " and "far $60^{\circ}$ " 


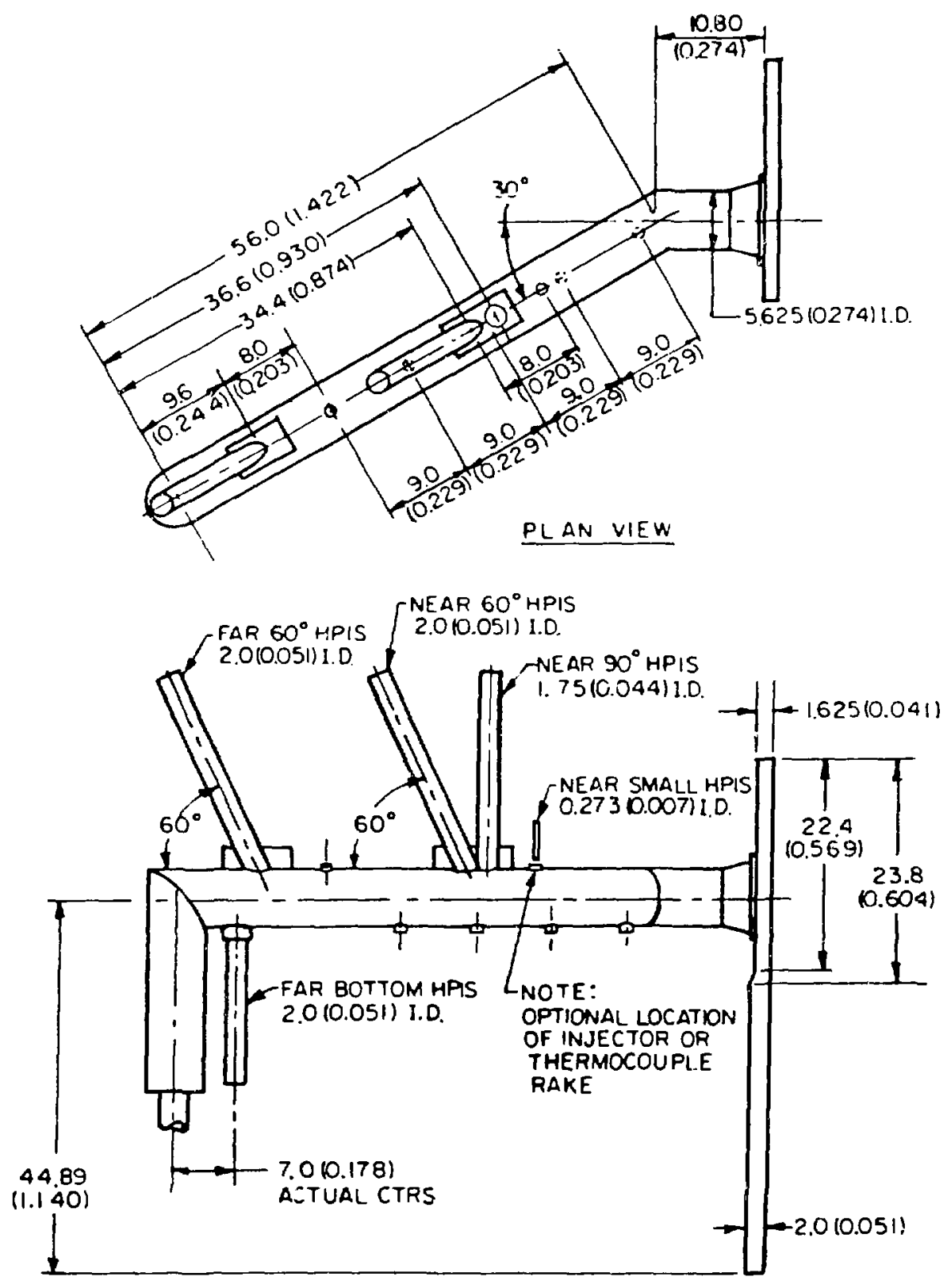

NOTE:

ALL DIMENSIONS ARE IN INCHES (METERS)

ELEVATION VIEW

FIGURE 1 Geometry of Creare 1/5-Seale Phase I Experimental Facility ${ }^{3}$ 
configurations model the typical geometry of Combustion Engineering plants, while the "near small" configuration models those of Westinghouse plants.

On examining Figure 1, the reader will appreciate that there are not three but five injectors available for possible study of the effect of injection location on mixing. However, two (designated "near $90^{\circ}$ " and "far bottom") were not used in these tests. The "near small" injector is a retrofit that uses the available hole for the alternate location of a thermocouple rake.

Water from the HPI supply is pumped into one of these injectors and flows through the cold leg and downeomer to be removed uniformly by a manifold at the bottom of the downeomer. The cold leg includes a $30^{\circ}$ bend in the horizontal plane and a nozzle similar to typical PWR nozzle geometries. The primary coolant is circulated by loop flow through the cold leg and toward the vessel. The loop flow proceeds upward in a vertical riser and bends $90^{\circ}$ to the horizontal direction as shown in Figure 1. Just after the bend to horizontal, the flow passes through a perforated plate of about $30 \%$ open area with holes of $3 / 16 \mathrm{in} .(0.005 \mathrm{~m})$ diameter. The intent of this plate is to provide a relatively uniform flow at the inlet to the cold leg. One series of two tests (Series F) was performed without this plate to simulate possible flow distortion caused by the primary coolant pump.

\section{INLET LENGTH ANALYSIS}

In both the generic full-scale PWR model computations and the Creare $1 / 5$-scale experiments, fully developed laminar flow was found not to exist. For a pipe of radius $\mathrm{R}$ and length $\mathrm{x}$ approximately $95 \%$ of fully developed laminar flow is obtained for inlet velocity $\mathrm{W}_{\mathrm{O}}$ and fluid kinematic viscosity $v={ }_{{ }_{1}} \mathrm{CL} /{ }^{10} \mathrm{CL}$ as ${ }^{5}$

$$
100 \frac{V x}{R^{2} W_{0}}-10
$$


For conditions typical of the Creare $1 / 5$-scale tests $\left(v=6 \times 10^{-7} \mathrm{~m}^{2} / \mathrm{s}\right.$ at $15^{\circ} \mathrm{C}, \mathrm{W}_{\mathrm{o}}=$ $0.016 \mathrm{~m} / \mathrm{s}, \mathrm{R}=0.0714 \mathrm{~m}$ ), the hydrodynamic entry length computed from Eq. (1) is $13.6 \mathrm{~m}$. The distance from the "far $60^{\circ}$ " injector, shown in Figure 1, to the thermocouple locations $\mathrm{T} 1$ through $\mathrm{T} 5$, near the exit of the cold leg shown in Figure 2, is approximately $1.6 \mathrm{~m}$. Hence, the velocity profile is a developing one; it looks turbulent because it is in the early entrance region. ${ }^{5}$ The computer code also produced a similar velocity profile. ${ }^{2}$ The cold leg Reynolds number, $\mathrm{Re}_{\mathrm{CL}}$, for the Creare experiments range from about $5 \times 10^{3}$ to $10^{5}$ which would lead one to conclude that the flow is turbulent. The above analysis shows this not to be the case. If the flow were turbulent (which it is not), the dictance required for fully developed turbulent flow is obtained from the relationship 6

$$
x / 2 R=0.693 R_{\text {LOOP }}^{1 / 4}
$$

For the conditions typical of the Creare 1/5-scale tests, one gets a length of $0.7667 \mathrm{~m}$. This is nearly equal to the lehgth from the "near small" injector shown in Figure 1 to the thermocouple locations T1 through T5 shown in Figure 2. 
For the generic full-scale PWR model computations, ${ }^{2}$ the entry length analysis produces:

\begin{tabular}{|c|c|c|}
\hline Item & $\mathrm{W}$ & $\mathrm{CE}$ \\
\hline $\mathrm{Fr}_{\mathrm{HPI}}$ & 0.04 & 0.14 \\
\hline${ }^{R e} \mathrm{CL}$ & $5.88 \times 10^{5}$ & $1.68 \times 10^{5}$ \\
\hline $\begin{array}{l}\text { Fully developed laminar } \\
\text { flow leng th }\end{array}$ & $12.84 \mathrm{~m}$ & $10.69 \mathrm{~m}$ \\
\hline $\begin{array}{l}\text { Length from tPI to exit } \\
\text { of cold leg: }\end{array}$ & $2.751 \mathrm{~m}$ & $3.658 \mathrm{~m}$ \\
\hline Total cold leg length & $7 \mathrm{~m}$ & $7 \mathrm{~m}$ \\
\hline
\end{tabular}

Hence, the length from the point of HPI to the exit of the cold leg is about $1 / 4$ of the length required for fully developed laminar flow. This value is higher than the roughly $1 / 10$ value found for the $1 / 5$-scale experiments. Hence, neither the fuil-scale generic model nor the $1 / 5$-scale experiments have fully deveioped laminar flow, but the former are more fully developed.

\section{THERMOCOUPLE RESPONSE ANALYSIS OF CREARE 1/5-SCALE PHASE II EXPERIMENTS}

The 20 Creare 1/5-Scale Phase II thermal and fluid mixing experiments ${ }^{3}$ having loop flow are analyzed in detail in this section. The observed temperature distributions and temperature fluctuations were used in the analysis with special attention paid to thermocouples T41, T44, T51, T54 and T35 located near the points of HPI and thermocouples T'1 through T5 located near the exit of the cold leg as shown in Figure 2. Thermocouples T51 through T54 could not be used when injection was in the "near small" injector. 


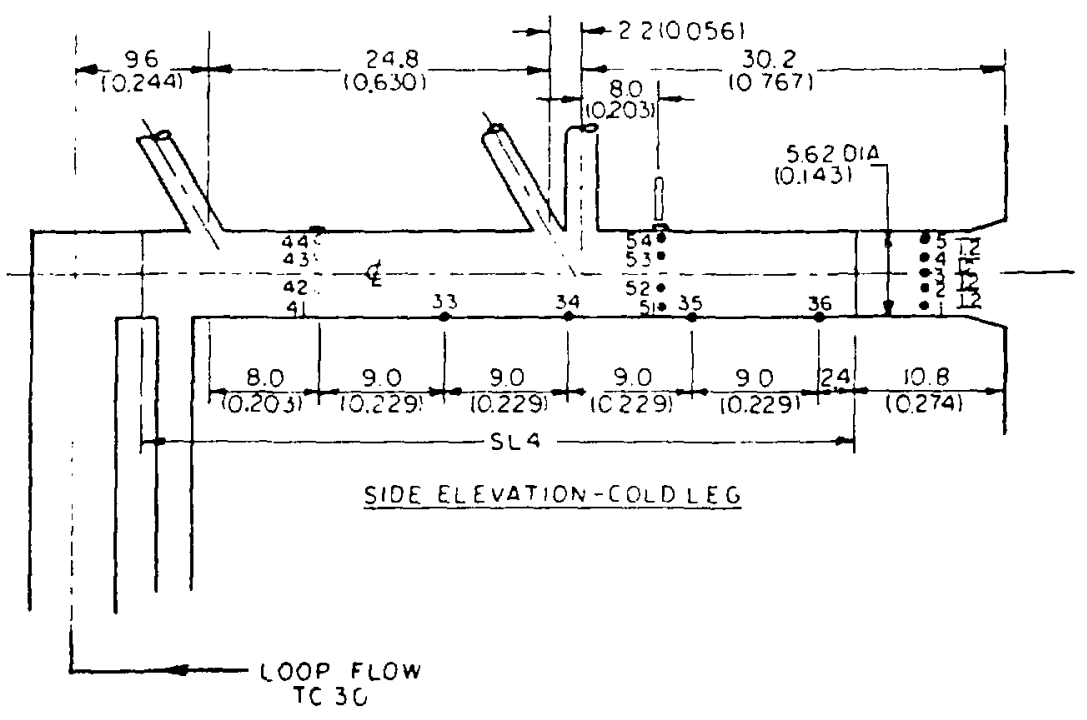

ALL DIMENSIONS ARE IN INCHES (METERS)

FIGURE 2 Creare 1/5-Scale Phase II Experimental Facility Thermocouple Locations in the Cold Leg ${ }^{3}$ 
The experiments show sizable eddy structure comparable to that shown in Figure 6.2 in Turner's book. ${ }^{7}$ Vortices tend to be introduced by the HPI water. There is also a tendency of the HPI jet to "streak" or "channel" forming large amplitude, low frequency undulations. This channeling is observable in the experiments from the dye injection studies and the thermocouple response data which show the cooler HPI plume sinking to the bottom of the cold leg surrounded by warmer loop flow water. The phenomena of a jet flowing into a cross flow was studied by Ramsey et al. ${ }^{8}$ and computed by Launder ${ }^{9}$ and Patankar et ai. ${ }^{10}$ This jet motion is in addition to any stream turbulence.

Gravity Controlled Mixing (Stratification) Regime: Injected cold fluid falls over a short distance to the bottom of the cold leg as shown in Figure 3a. For the case of the "near $60^{\circ}$ injector, thermocouple location $\mathrm{T} 51$ shows the largest fluctuations. The corresponding thermocouple locations for the "far $60^{\circ}$ " and "near small" injectors are T41 and T35, respectively. However, thermocouple location T54 (or T44) shows little, if any, fluctuations and no response. Fluid at the exit becomes stratified as indicated by thermocouples T1 through T5. There is warm water flowing into the top of the cold leg from the downcomer contercurrently to the cooler water flowing out of the cold leg. Figure 4 shows these temperature fluctuations for Test No. 51 which is an example of a gavity controlled mixing (stratification) run. Test numbers $41,42,46,51,53,55,66,62$, and 63 fall into this mixing regime.

Momentum Controlled Mixing Regime: The injected cold fluid is carried forward by the momenturn of the hot fluid in the cold leg with the formation of temperature eddies causing mixing as shown in Figure $3 \mathrm{~b}$. This time there are large fluctuations in temperature at thermocouple iocation T54 (or T44), while there are relatively none at thermocouple location T51 (or T41) and little response. This is opposite to the gravity 


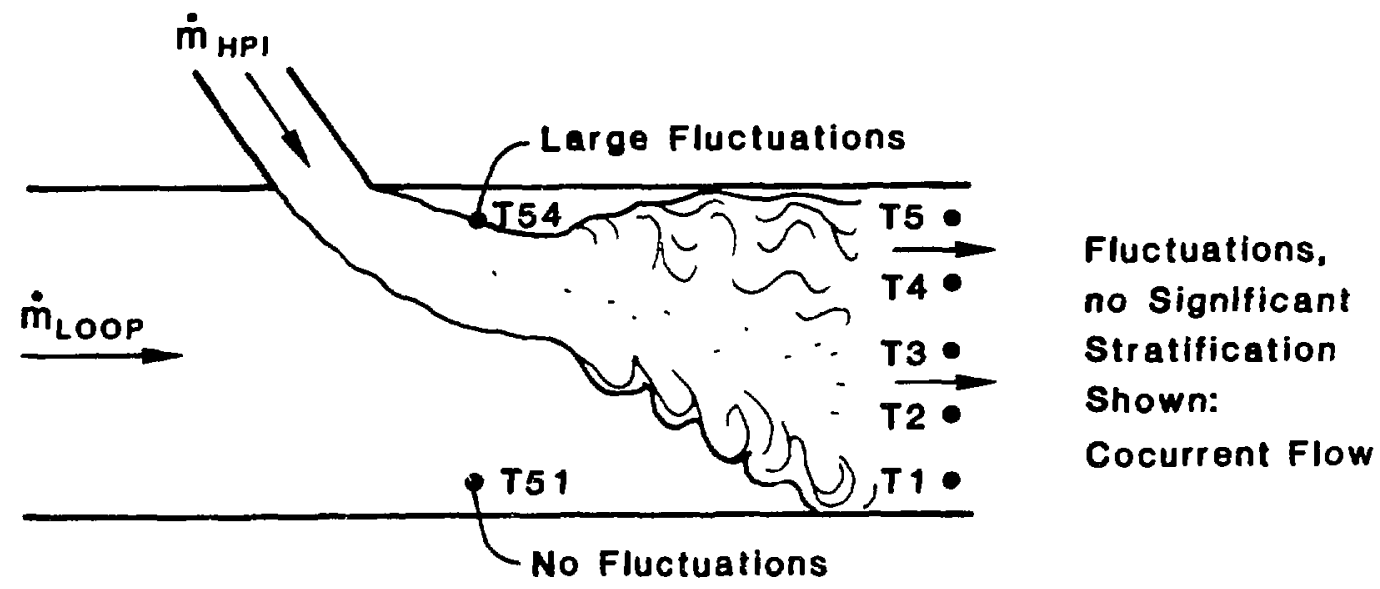

FIGURE 3a Gravity Controlled Mixing (Stratification) Regime (low $\dot{\mathrm{m}}_{\mathrm{LOOP}} / \dot{\mathrm{m}}_{\mathrm{HPI}}$ )

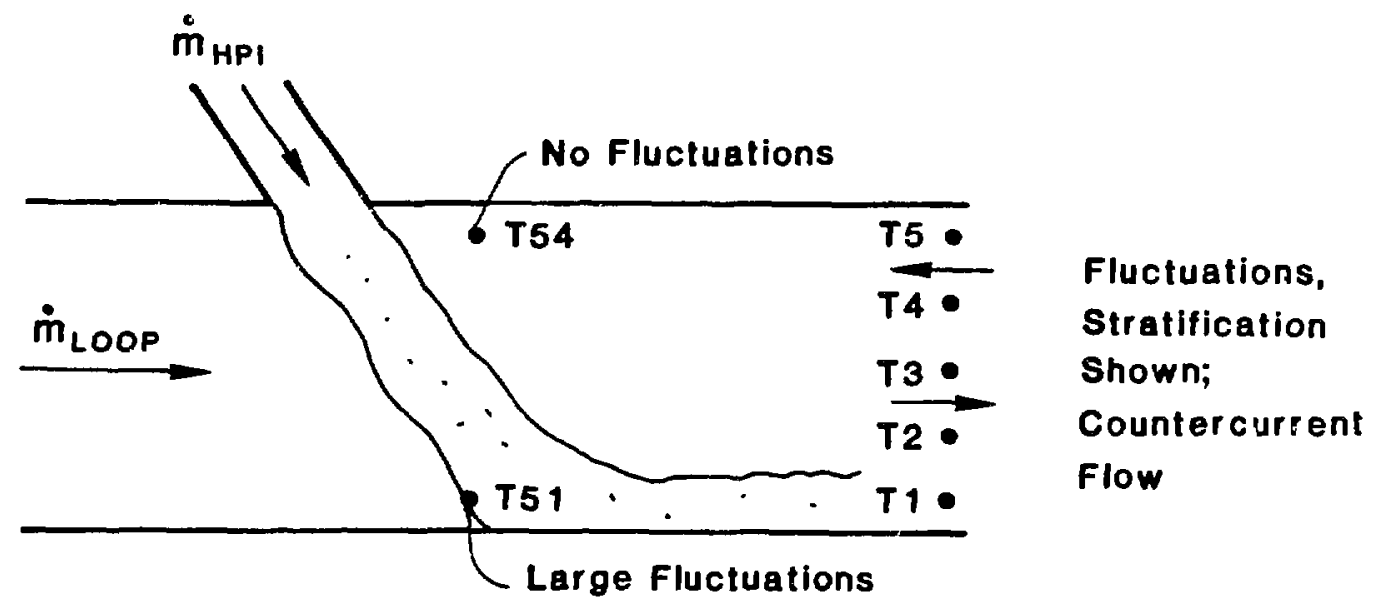

FIGURE 3b Momentum Controlled Mixing Regime (high $\dot{\mathrm{m}}_{\text {LOOP }} / \dot{\mathrm{m}}_{\mathrm{HPI}}$ )

FIGURE 3 Mixing Regimes in a Cold Leg with HPI (not to scale) 


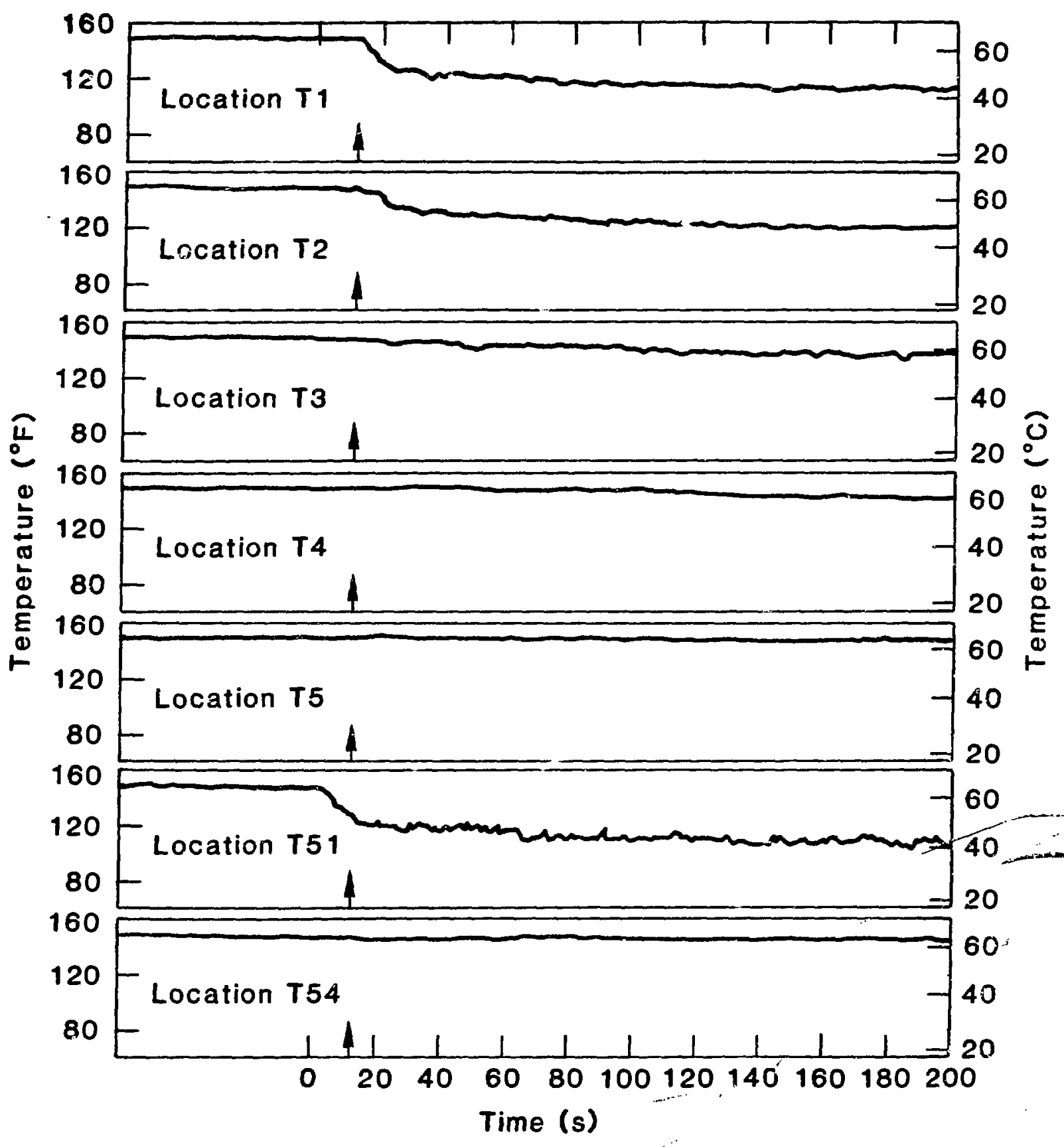

Time 0 Indicates HPI

Arrow Indicates Dye aft Cold Leg Nozzle Rake

FIGURE 4 Creare 1/5-Scale Phase $n$ Test No. 51 Thermocouple Response Data ${ }^{3}$ 
controlled mixing regime. The fluid at the exit flow co-currently and undergoes continuous fluctuations with little or no thermal stratification as indjeated by thermocouples T1 through T5. Figure 5 shows these temperature fluctuations for Test No. 47, which is an example of momentum coltrolled wixing run. Test numbers Cases $43,44,52,47,48,56,58,59$, and 60 fall into this regime.

Neutral Regime: Test numbers 54 and 65 indicate both of the above effects are at play. Fluctuations are indicated by both thermocouple T51 and T54 (or T41 and T44). Stratification at the exit is not prominent, nor is the mixing violent.

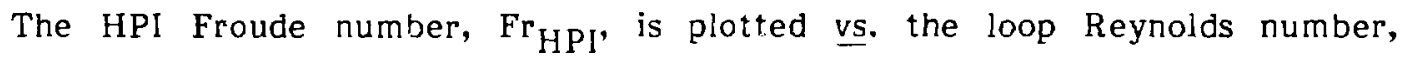
$\mathrm{Re}_{\text {LOOP }}$ for all 20 cases in Figure 6. Even though the data points are sparse, the gravity and the momentum controlled regimes fall distinetly into two portions with the neutral cases in between. The dividing line is given by

as suggesı ad by Martin (p. 83 of Turner). ${ }^{7}$ The value of 6.77 was determined from where the points of test numbers 54 (neutral), 42 (gravity controlled), and 59 (momentum controlled) coincide. It appears that for the combination of loop Reynolds number and Froude number such that the opes ating point is above the dividing line, the cold fluid tends to be carried forward without sinking while traveling over to thermocouple T54 (or T44), but becomes mixed with the hot fluid toward the exit. Below the dividing line, the cold fluid sinks to the bottom of the cold leg and the fluid remains stratified toward the exit where the downcomer fluid may enter. 


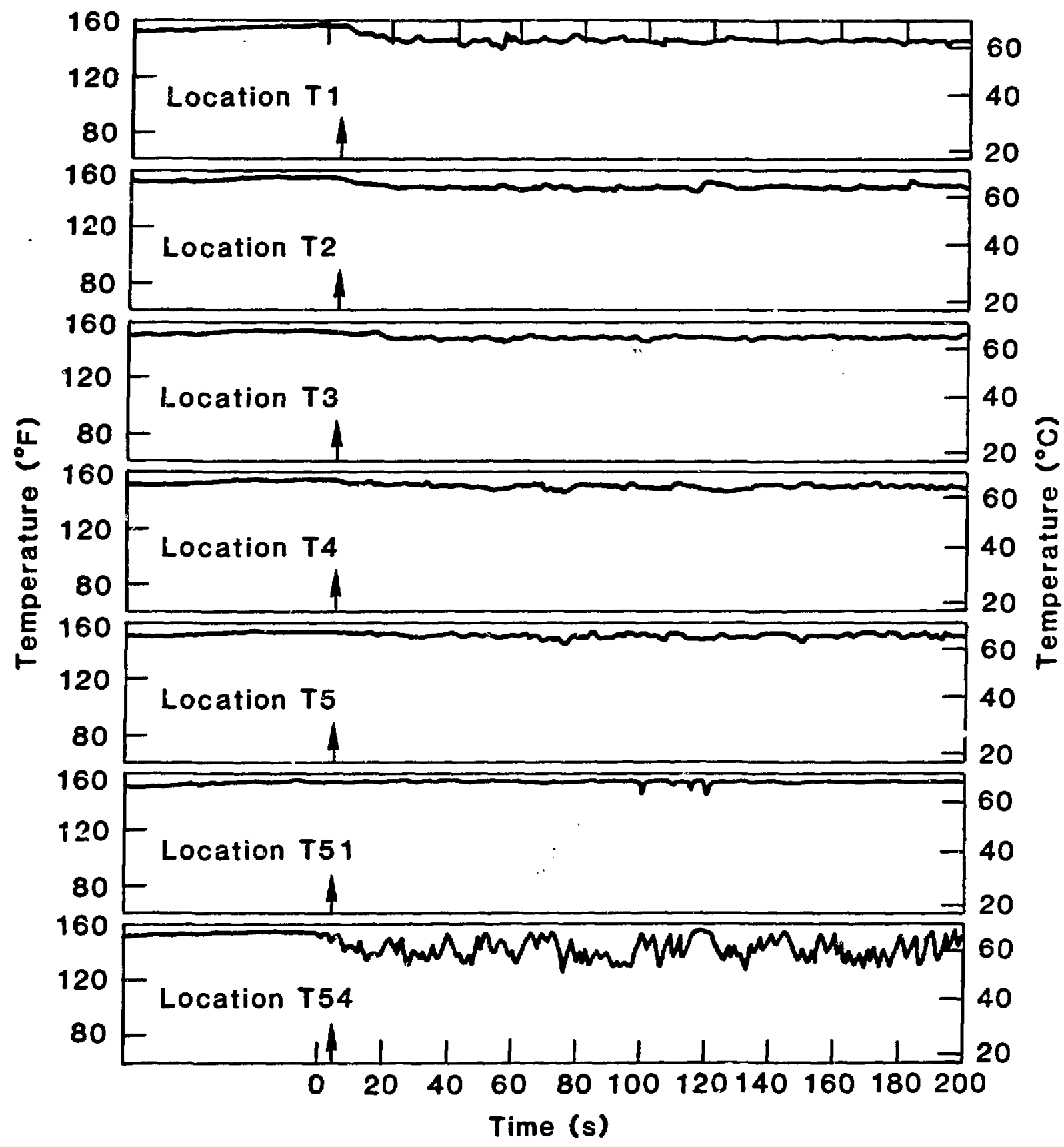

Time 0 Indicates $\mathrm{HPI}$

Arrow Indicates Dye at Cold Leg Nozzle Rake

FIGURE 5 Creare 1/5-Seale Phase II Test No. 47 Thermocouple Response Data ${ }^{3}$ 


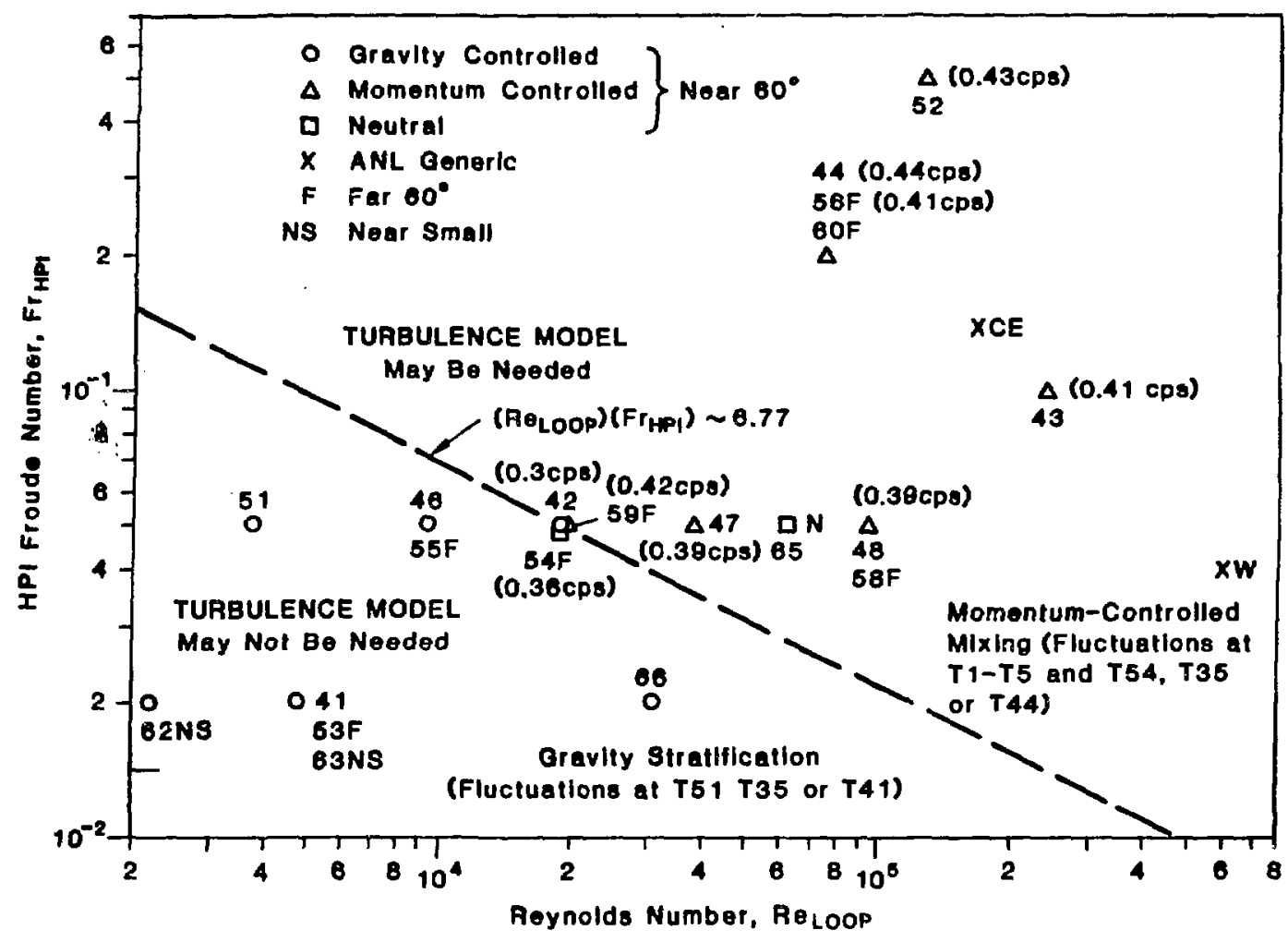

FIGURE 6 Regimes of Creare 1/5-Seale Phase II Tests and Generic Full-Seale PWR Model Computations 
Also noted in Figure 6 are the frequencies of the fluctuations, principally at thermocouple T54 (or T44) for cases above the dividing line and at thermocouple T51 (or T41) for cases below the dividing line. The range of 0.3 to 0.44 cycles per second of the basic mode could be due to vortex motion induced by the cold jet 8 and appears to increase for cases far above the dividing line. The frequency could have been influenced by the heat capacitance of the thermocouple probes which absorb high frequency fluctuations. These fluctuations may be treated as thermal wakes. ${ }^{11}$

Also shown in Figure 6 are cases identified as "ANL Generic" which refers to the generic full-scale PWR model computations. ${ }^{2}$ Conditions the CE and $W$ models remain to be determined because of significantly different dimensions from the $1 / 5$-scale tests, and the different pipe lengths required for fully developed flow.

One notes that an important omission in the Creare $1 / 5-$ Scale Phase Il tests is the study of dye mixing of two streams of equal temperature at various $\mathrm{Q}_{\mathrm{LOOP}} / \mathrm{Q}_{\mathrm{HPI}}$ * Such a study is important because identical diffusivity of dye to that of thermal diffusivity is not to be expected. Tests involving pure dye mixing will provide a means for differentiating between these two effects.

\section{COLD PLUME FROM HPI ANALYSIS}

To further explore the condition of stratification or mixing of HPI in the cold leg, the interaction of momentum and gravity can be seen from comparing the hypothetical plume centerline in a large flow domain similar to a plume from a smoke stack. The following model is based on the work of Hoult et al. ${ }^{12}$ based on Baines ${ }^{13}$ and Morton et al. ${ }^{14}$ The plume centerline shown in Figure 7 over a length of the cold leg, ${ }^{\ell}$, will reach the point $z_{m}$ by momentum transfer and the point $z_{g}$ by gravity effect with convection. These points are given by the following approximate relations:

$$
z_{g}=\left[2.344 F_{H} \ell_{3}^{2}\right]^{1 / 3} / V_{C L}
$$




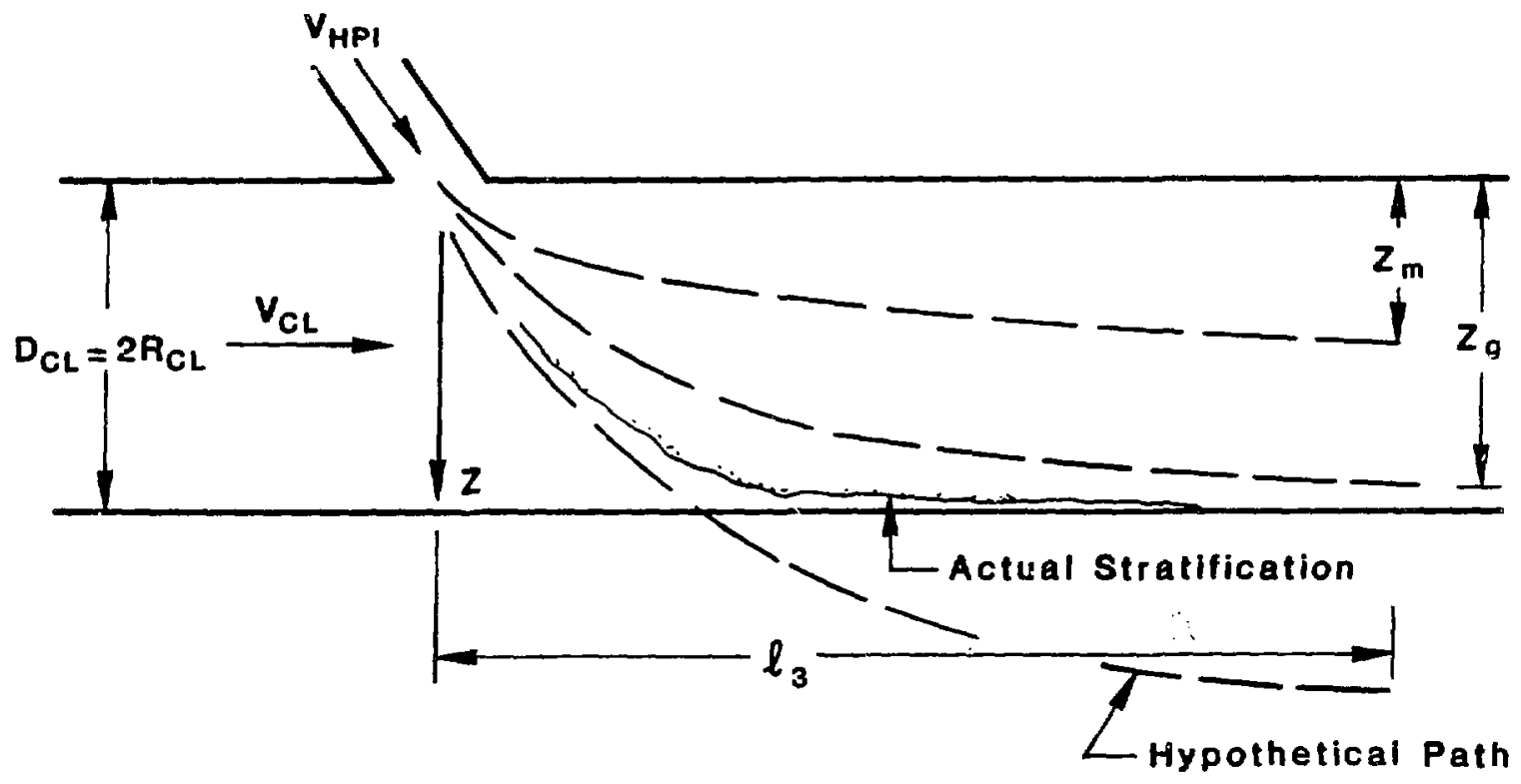


and

$$
z_{m}=\left[\begin{array}{lll}
V_{H P I} & R_{H P I} & e_{3} / V_{C I}
\end{array}\right]^{1 / 2}
$$

where

$$
F_{H}=V_{H P I} R_{H P I}^{2}(\Delta \rho / \rho) g
$$

For $\mathrm{z}^{\sim} \mathrm{D}_{\mathrm{CL}}=2 \mathrm{R}_{\mathrm{CL}}$ the plume will be near the bottom. The Creare $1 / 5$-scale tests and generic full-scale PWR model computations cases are replotted in Figure 8 with $\mathrm{z}_{\mathrm{g}}$ and $\mathrm{z}_{\mathrm{m}}$ plotted vs. $\mathrm{Fr}_{\mathrm{HPI}}$. Points to the left of $\mathrm{D}_{\mathrm{CL}}$ indicate that the plume will not reach the bottom of the cold leg at its exit while those to the right of $\mathrm{D}_{\mathrm{CL}}$ indicate that the plume will fall to the bottom of the cold leg at its exit. Direct calculation of the jet path in the pipe has to be made numerically. ${ }^{2,12}$

Comparison of Figure 8 with Figure 6 shows that to the left of $\mathrm{D}_{\mathrm{CL}}$, most of the test points agree with those in the momentum controlled mixing regime and those to the right fall in the gravity mixing regime. Note that the generic full-scale model computation for $C E$ tends to stratify, while the $W$ case tends to mix. In other words, the line $\mathrm{Re}_{\mathrm{LOOP}}{ }^{1 / 2} \mathrm{Fr}_{\mathrm{HPI}}=6.77$ in Figure 6 is only applicable to the Creare 1/5-scale experiments because of the differences in geometry, $W$ and $C$ will have a different line separating the two regimes.

\section{Linear Stability Analysis}

Gage and Reid ${ }^{15}$ performed a linear stability analysis for fully developed poiseuille flow of a stably thermally stratified fluid between two infinite parallel plates. They found that the minimum critical Reynolds number, $\mathrm{Re}_{\mathrm{cr}}$, on the neutral stability curve increased with density difference. Above a certain Richardson number, Ri (which can be related to the inverse of the Froude number, $\mathrm{Fr}_{\mathrm{HPI}}$ ) the flow was found to be stable for all Reynolds numbers, as shown in Figure 9. Phenomenologically, this 


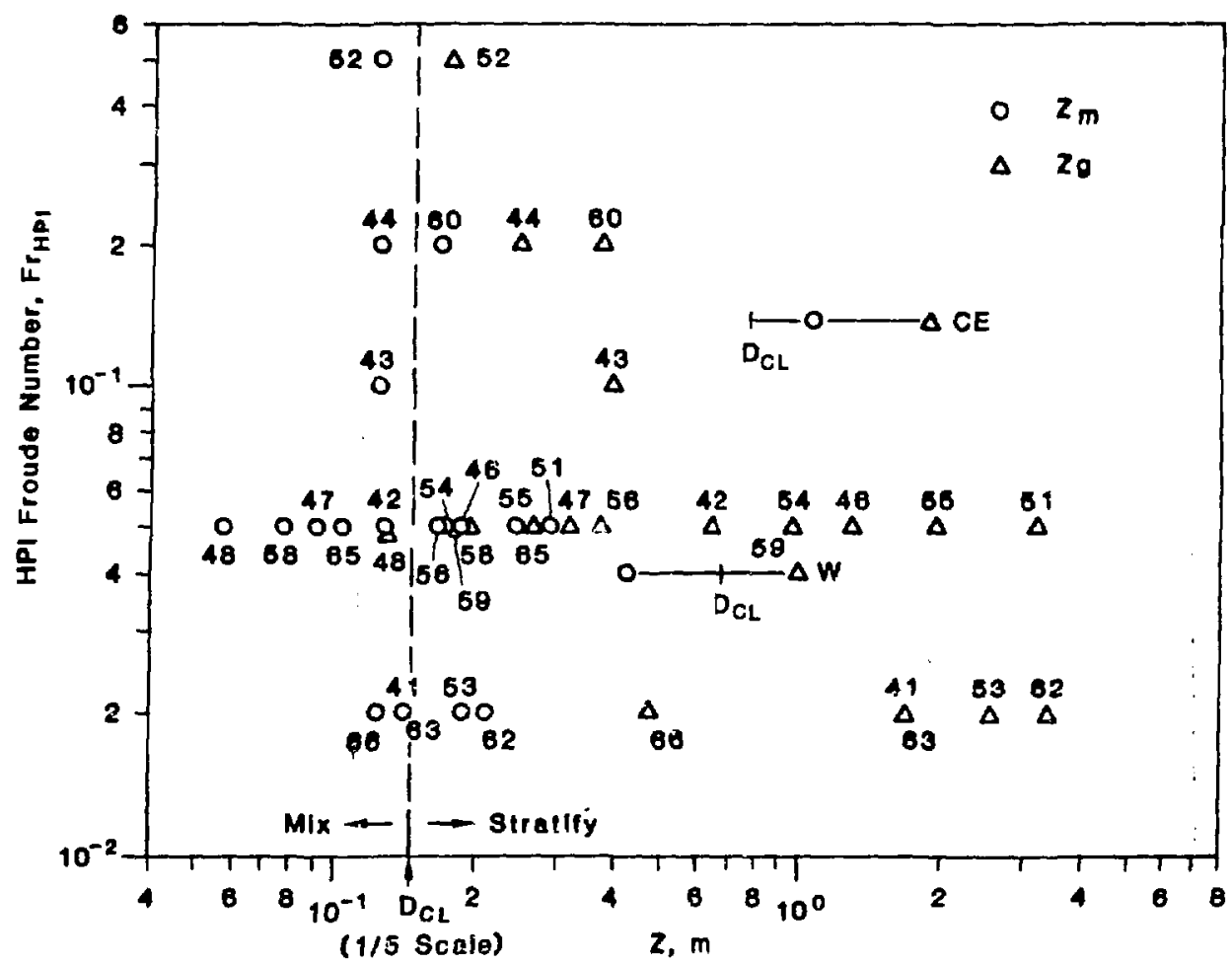




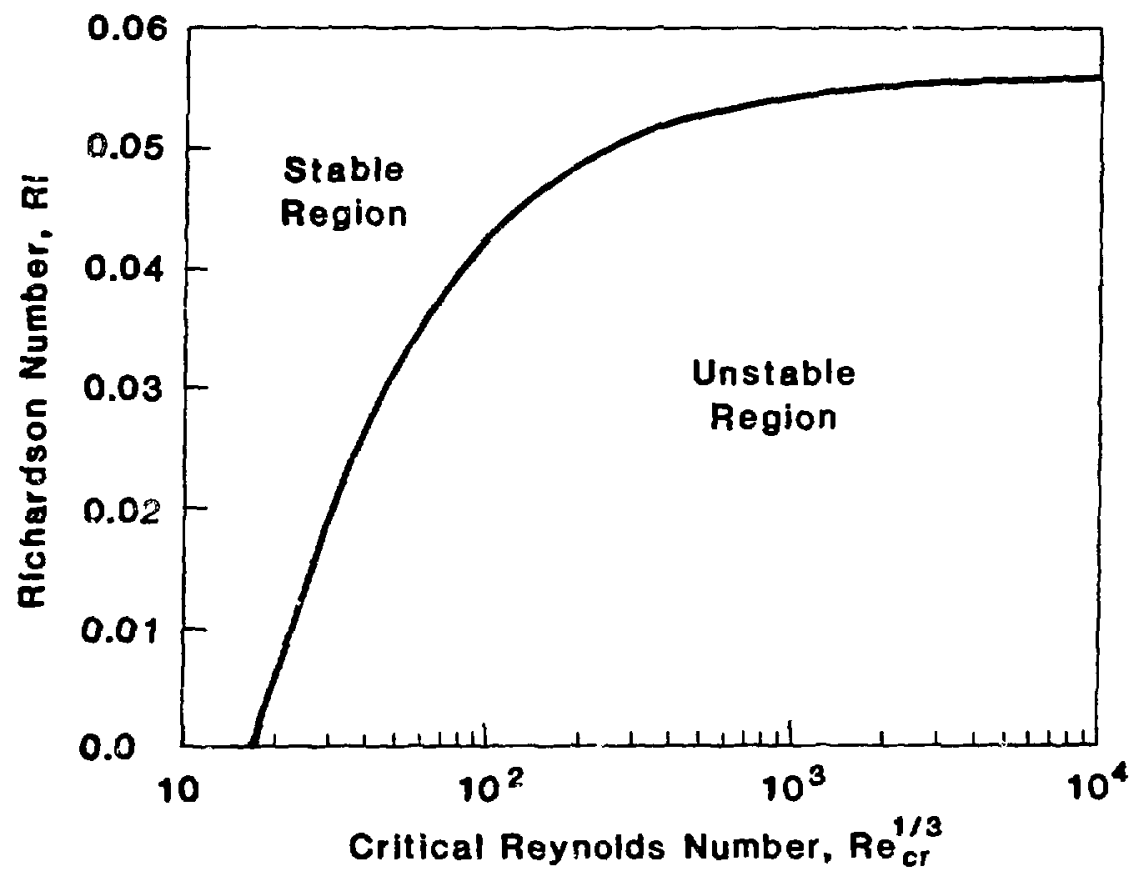

FIGURE 9 The Variation of the Minimum Central Reynolds Number with the Richardson Number 15 
means that small disturbances introduced into the flow are damped by bunyancy effects and hence turbulence is suppressed.

We analyzed the Creare 1/5-Scale Phase 11 test runs simulated by Lyczkowski et al. ${ }^{2}$ The results are shown below:

\begin{tabular}{lrrrrr}
$\begin{array}{l}\text { Run } \\
\text { No. }\end{array}$ & ${ }^{R e}{ }_{\mathrm{CL}}$ & ${ }_{\mathrm{m} / \mathrm{S}}^{V_{\mathrm{S}}}$ & ${ }^{\Delta T_{\mathrm{CL}}}$ & $\mathrm{Ri}$ & ${ }^{\mathrm{Re}}{ }_{\mathrm{Cr}}$ \\
\hline 62 & 4,400 & 0.0123 & 45 & 1.19 & $\infty^{\infty}$ \\
63 & 7,900 & 0.0221 & 45 & 0.37 & $\infty$ \\
51 & 8,600 & 0.0242 & 45 & 0.31 & $\infty$ \\
47 & 60,000 & 0.1659 & 45 & 0.0065 & 20 \\
\hline
\end{tabular}

The Richardson number was computed from

$$
\mathrm{Ri}=\mathrm{g} \propto \mathrm{D}_{\mathrm{CL}} \Delta \mathrm{T}_{\mathrm{CL}} / 64 \mathrm{~V}_{\mathrm{CL}}^{2}
$$

where $\alpha$ is the coefficient of expansion of water $\left(0.18 \times 10^{-3{ }^{\circ}} \mathrm{C}^{-1}\right) . \Delta \mathrm{T}_{\mathrm{CL}}$ was taken to be $45^{\circ} \mathrm{C}$ which is the nominal temperature difference between the HPI and entering cold leg water. From these results we estimated test numbers 62,63 , and 51 to be laminarized using the linear stability analysis.

Test number 47 is definitely turbulent. This analysis tends to be backed up by the limited data of Johnston ${ }^{16}$ and Bradshaw ${ }^{17}$ as presented by Rothe ${ }^{18}$ which show turbulence suppression for stably stratified flow. No turbulence modeling was used to computer model any of the tests to be on the conservative side because of uncertainties and lack of guidelines in modeling turbulence for highly nonisothermal buoyancy driven flows. 
These laminarized test runs fall into the grav $\_$controlled mixing (stratification) regime in Figure 6, while test number 47 lies in the momentum controlled mixing regime. We therefore speculate that no turbulence model may be needed to model gravity controlled mixing while some turbulence model may be necessary to model momentum controlled mixing.

\section{CONCLUSIONS}

The nature of experimental modeling of HPI injection is seen to be influenced by:

1. Injection Froude number;

2. Loop flow Reynolds number;

3. Flow passage length in relation to hydrodynamic entrance length;

4. Jet plume geometry in relation to cold leg geometry.

By correlating items 1 and 2, one can make an estimation of the extent of stratification or mixing (Figure 6). Not only cannot items 1 and 2 be satisfied at the same time but item 3 influences the correlation of items 1 and 2. Estimation of momentum and gravity controlled mixing regimes for different geometry has to be assisted by the trend in jet paths, item 4. General agreement in trends for the Creare 1/5-Scale Phase II experiments using the thermccouple respense data and the plume analysis (Figures 6 and 8 ) is noted. The results of the linear stability analysis also appears to correlate gravity and momentum mixing regimes. A stable situation corresponds to gravity mixing while an unstable situation compares to momentum mixing. The linear stability analysis may be used as a guide for turbulence modeling.

\section{ACKNOWLEDGMENT}

A portion of this work was performed under a contract from the Electric Power Research Institute (Research Project 2122-1), J.H. Kim, Project Manager. 


\section{NOMENCLATURE}

${ }^{\mathrm{A}} \mathrm{CL}$ Cold leg pipe cross-sectional area

${ }_{\text {HPI }}$ High pressure injection pipe cross-sectional area

$\mathrm{D}_{\mathrm{CL}}$ Cold leg pipe diameter

$\mathrm{F}_{\mathrm{HPI}} \quad$ Froude number of $\mathrm{HPI},=\left(\mathrm{Q}_{\mathrm{HPl}} / \mathrm{A}_{\mathrm{CL}}\right) /\left[\left(\Delta_{0} / \rho\right) \mathrm{gD}_{\mathrm{CL}}\right]^{1 / 2}$

g Acceleration due to gravity

HPI High pressure injection

$\ell_{3}$ Distance from HPI in cold leg to exit

$\dot{\mathrm{m}}_{\mathrm{HPI}}$ High pressure injection mass flow rate

$\dot{\mathrm{m}}_{\text {LOOP }}$ Loop mass flow rate

$\mathbf{Q}_{\text {HPI }}$ High pressure injection volumetric flow rate

$\mathrm{Q}_{\text {LOOP }}$ Loop volumetric flow rate

$\mathrm{Re}_{\mathrm{CL}}$ Reynolds number of combined HPI and loop flow in cold leg =

$D_{\mathrm{CL}} v_{\mathrm{CL}}{ }^{\rho} \mathrm{CL} /{ }^{\prime \mu} \mathrm{CL}$

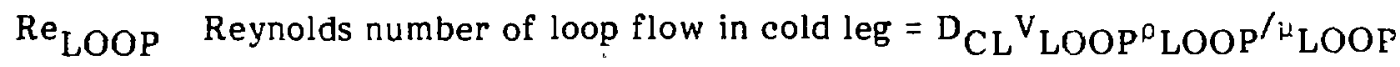

$\mathrm{R}_{\mathrm{HPI}}$ High pressure injection pipe radius

$\mathrm{Ri} \quad$ Richardson number $=\mathrm{gaD}_{\mathrm{CL}} / 64 \mathrm{VCL}^{2}$

$\Delta T_{C L}$. Temperature difference between HPI temperature and inlet cold leg temperature

$\mathrm{V}_{\mathrm{CL}}$ Velocity of combined HPI and loop flow in cold leg $\left(\mathrm{Q}_{\mathrm{LOOP}}{ }^{\circ} \mathrm{LOOP}{ }^{+}\right.$ $\left.\mathrm{Q}_{\mathrm{HPI}}{ }^{\rho} \mathrm{HPl}\right) / \mathrm{A}_{\mathrm{CL}}{ }^{\circ} \mathrm{CL} \cong\left(\mathrm{Q}_{\mathrm{LOOP}}+\mathrm{Q}_{\mathrm{HPl}}\right) / \mathrm{A}_{\mathrm{CL}}$ for a wide range of temperatures

$\mathrm{V}_{\text {LOOP Velocity of loop flow in cold leg }}=\mathrm{Q}_{\mathrm{LOOP}} / \mathrm{A}_{\mathrm{CL}}$

$\mathrm{V}_{\mathrm{HPI}}$ Velocity of high pressure injection flow $=\mathrm{Q}_{\mathrm{HPI}} / \mathrm{A}_{\mathrm{HPl}}$

a Coefficients volumetric expansion

${ }^{\circ} \mathrm{CL}$ Density of combined loop flow and high pressure injection flow in the cold leg ${ }^{\circ}$ LOOP Density of loop flow 
$\Delta \rho$ Density difference between high pressure injection flow and loop flow $=$ ${ }^{\circ}$ HPI ${ }^{-}{ }^{\circ}$ LOOP

- Density of loop flow, ${ }^{\circ}$ LOOP

${ }^{\mu} \mathrm{CL}$ Viscosity of combined loop flow and high pressure injection flow

$\mu_{L O O P}$ Viscosity of loop flow 


\section{REFERENCES}

1. Marston, T., K.H. Sun, and B. Chexal, EPRI Pressurized Thermal Shock Program Status and Review, presented at the 9th USNRC Water Reactor Safety Review Meeting, Gaithersburg, Md. (Oct. 1981).

2. Lyezkowski, R.W., C.C. Miao, H.M. Domanus, J.R. Hull, W.T. Sha, and R.C. Schmitt, Three-Dimensional Analysis of Thermal and Fluid Mixing in Cold Leg and Downcomer of BWR Geometries, Electric Power Research Institute, Interim Report NP-3321, Research Project 2122-1 (Dec. 1983).

3. Rothe, R.H., M.F. Ackerson, and J.A. Block, Fluid and Thermal Mixing in a Model Cold Leg and Downcomer with Loop Flow, Electric Power Research Institute, Interim Report NP-2312 (April 1982).

4. Domanus, H.M., R.C. Schmitt, W.T. Sha, and V.L. Shah, COMMIX-1A: A ThreeDimensional Transient Single-Phase Computer Program for Thermal Hydraulic Analysis of Single and Multicomponent Systems, Vol. I: Users Manual, Argonne National Laboratory Report ANL-82-25 Vol. I, NUREG/CR-2896 Vol. I (Dec. 1983).

5. Schlichting, H., Boundary Laver Theory, 6th Ed., McGraw Hill, p. 177 (1968).

6. Hinze, J.O., Turbulence, McGraw-Hill (1975).

7. Turner, J.S., Bucyancy Effects in Fluids, Cambridge Univ. Press, Cambridge (1973).

8. Ramsey, J.W., and R.J. Goldstein, Interaction of a Heated Jet with a Deflecting Stream, NASA-CR 72613 (1970).

9. Launder, B.E., On the Effects of a Gravitational Field on the Turbulent Transport of Heat and Momentum, J. Fluid Mech.,67(3) pp. 569-581 (1975).

10. Patankar, S.V., P.K. Basu, and S.A. Alpay, Prediction of the Three-Dimensional Velocity Field of a Deflected Turbulent Jet, J. Fluids Eng. Trans ASME (Dec. 1977). 11. Tennekes, H., and J.L. Lumley, A First Course in Turbulence, MIT Press, p. 242 (1972). 
12. Hoult, D.P., J.A. Fay, and L.J. Forner, A theory of Plume Rise Compared with Field Observations, Air Pollution Control Assoc. paper No. 68-77 (1968).

13. Baines, W.D., Entrainment from a Density Interface by a Plume or Jet, J. Fluid Mech. (1972).

14. Morton, B.R., G.I. Taylor, and J.S. Turner, Turbulent Gravitational Convection from Maintained and Instantaneous Sources, Proc. Roy. Soc. A234, pp. 1-23 (1956).

15. Gage, K.S., and W.H. Reid, The Stability of Thermally Stratified Plane Poiseuille Flow, J. Fluid Mech., 33(1) pp. 21-32 (1968).

16. Johnston, J.P., J. Fluid Eng., 95(2) (1973).

17. Bradshaw, P., AGARD Monograph AGARD-AG-169 (1973).

18. Rothe, P.H., Thermal Fluid Scaling Analysis, presented at NRC Advanced Code Review Group Meeting, Bethesda (April 21, 1981). 